Article

\title{
Gamma Radiation Effects on Peanut Skin Antioxidants
}

Adriano Costa de Camargo ${ }^{1, *}$, Thais Maria Ferreira de Souza Vieira ${ }^{2}$, Marisa Aparecida Bismara Regitano-D’Arce ${ }^{2}$, Maria Antonia Calori-Domingues ${ }^{2}$ and Solange Guidolin Canniatti-Brazaca ${ }^{2}$

1 Center for Nuclear Energy in Agriculture, University of São Paulo (CENA/USP), Av. Centenário 303, P.O. Box 96, 13400-970, Piracicaba, SP, Brazil

2 Department of Agri-Food Industry, Food \& Nutrition, "Luiz de Queiroz" College of Agriculture (ESALQ/USP), University of São Paulo, Av. Pádua Dias 11, P.O. Box 9, CEP 13418-900, Piracicaba, SP, Brazil; E-Mails: tvieira@usp.br (T.M.F.S.V.); marisadarce@usp.br (M.A.B.R.-D.); macdomin@esalq.usp.br (M.A.C.-D.); sgcbraza@usp.br (S.G.C.-B.)

* Author to whom correspondence should be addressed; E-Mail: adrianoesalq@ gmail.com; Tel.: +55-19-9122-3234.

Received: 21 December 2011; in revised form: 29 February 2012 / Accepted: 1 March 2012 / Published: 7 March 2012

\begin{abstract}
Peanut skin, which is removed in the peanut blanching process, is rich in bioactive compounds with antioxidant properties. The aims of this study were to measure bioactive compounds in peanut skins and evaluate the effect of gamma radiation on their antioxidant activity. Peanut skin samples were treated with $0.0,5.0,7.5$, or $10.0 \mathrm{kGy}$ gamma rays. Total phenolics, condensed tannins, total flavonoids, and antioxidant activity were evaluated. Extracts obtained from the peanut skins were added to refined-bleached-deodorized (RBD) soybean oil. The oxidative stability of the oil samples was determined using the Oil Stability Index method and compared to a control and synthetic antioxidants (100 mg/kg BHT and $200 \mathrm{mg} / \mathrm{kg}$ TBHQ). Gamma radiation changed total phenolic content, total condensed tannins, total flavonoid content, and the antioxidant activity. All extracts, gamma irradiated or not, presented increasing induction period (h), measured by the Oil Stability Index method, when compared with the control. Antioxidant activity of the peanut skins was higher than BHT. The present study confirmed that gamma radiation did not affect the peanut skin extracts' antioxidative properties when added to soybean oil.
\end{abstract}

Keywords: peanut skin; residue; antioxidant activity; soybean oil; lipid oxidation 


\section{Introduction}

Peanut skins are waste from the blanching process of peanuts, which are recognized for their bioactive compounds' antioxidative properties. Although these skins are a potential source for natural antioxidants, they have only been used for animal feed. Proanthocyanidins [1] and flavonoids [2] have been isolated from the water-soluble fraction of peanut skins. Radical scavenging activity in relation to the content of total phenolic compounds and trans-resveratrol in fractions from ethanolic extracts of peanut skins was reported [3]. Proanthocyanidins isolated from the water-soluble fraction of peanut skins exhibited antioxidant activity [4]. The optimization of the extraction conditions for the recovery of antioxidant compounds from peanut skins was reported and ethanol was the most efficient solvent for peanut skin extraction, followed by methanol and water [5]. A study [6] found that phenolic compounds extracted from peanut skins could significantly reduce the oxidation of meat products and extend their storage stability. While the blanching process influences both the total phenolic and isolated procyanidin contents [7], the total phenolics and procyanidins present in skins that were peeled by hand or by roasting presented concentrations comparable to those found in grape seeds. In addition, the total antioxidant activity and free radical scavenging capacities of peanut skin extracts were all higher than those of Trolox or Vitamin $\mathrm{C}$ at equivalent concentrations.

Proanthocyanidin dimers and trimers from peanut skins can interact with membrane phospholipids, presumably with their polar headgroup. As a consequence of this interaction, they can provide protection against the attack of oxidants and other molecules that challenge the bilayer's integrity [8]. Phenolic compounds extracted from defatted peanut skins presented a greater protective effect against the hemolysis of red blood cells than ascorbic acid under in vitro conditions [9].

Some studies have shown increased antioxidant activity in gamma irradiated products [10-14]. Furthermore, peanut skins samples are susceptible to microbial contamination which can be reduced with gamma radiation. This is already done successfully with spices. The objective of this study was to evaluate the effect of gamma radiation on peanut skins from the blanching process, with a focus on bioactive compounds and antioxidant properties. Total phenolics, total flavonoids, condensed tannins, and in vitro antioxidant activity were determined in the peanut skins. Additionally, the antioxidant activity of the peanut skin extract in soybean oil, a model system for the Oil Stability Index, was measured using Rancimat.

\section{Results and Discussion}

\subsection{Polyphenols and Antioxidant Activity}

Total phenolic content, condensed tannin, and total flavonoid content of peanut skin extracts are shown in Table 1. It has been noted in the literature that the amount of polyphenols is different for each peanut product. In gallic acid equivalents, peanut skins presented total phenolic content ranging from 97.0 [9] to 143.6 [15]. These values are in agreement with the present study. With regards to the irradiation process, a noticeable increase in total phenolic content at 7.5 and $10.0 \mathrm{kGy}$ was observed. Also a positive correlation was found between gamma radiation doses and total phenolic content $(r=0.6905, p<0.05)$. Two of the most common monofloral Malaysian honeys that were gamma irradiated with $25.0 \mathrm{kGy}$ exhibited a two- or three-fold increase in their total phenolic contents [16]. 
Even doses as low as $2.0 \mathrm{kGy}$ were able to increase the total phenolic content in peaches [17]. However, no significant effect was observed in the total phenolic content of radiation-processed tea leaves $(0.0,1.0,2.0,5.0$, and $10.0 \mathrm{kGy})$ [18]. Similar results were noticed in the phenolic compounds of the green tea leaf and its byproduct after a $20.0 \mathrm{kGy}$ irradiation [19]. Any differences among herbs gamma irradiated at 5.0, 10.0, or $15.0 \mathrm{kGy}$ were found in terms of total phenolics and total flavonoids [20]. However, irradiation of almond skins with [11] doses of 4.0, 8.0, or $12.0 \mathrm{kGy}$ increased total phenolics in samples purchased from Blue Diamond Growers and, likewise, doses of 12.7 or $16.3 \mathrm{kGy}$ irradiated on samples purchased from Campos Brothers.

Table 1. Polyphenols of gamma-irradiated peanut skin extracts ${ }^{1}$.

\begin{tabular}{lcccc}
\hline & $\mathbf{0 . 0} \mathbf{~ k G y}$ & $\mathbf{5 . 0} \mathbf{~ k G y}$ & $\mathbf{7 . 5} \mathbf{k G y}$ & $\mathbf{1 0 . 0} \mathbf{k G y}$ \\
\hline $\mathrm{TPC}^{2}(\mathrm{mg} \mathrm{GAE} / \mathrm{g})$ & $79.36 \pm 1.94 \mathrm{c}^{3}$ & $80.73 \pm 2.07 \mathrm{bc}$ & $88.31 \pm 2.29 \mathrm{a}$ & $84.70 \pm 1.32 \mathrm{ab}$ \\
$\mathrm{CT}(\mathrm{mg} \mathrm{CAT} / \mathrm{g})$ & $230.43 \pm 4.65 \mathrm{a}$ & $203.71 \pm 0.84 \mathrm{c}$ & $209.33 \pm 2.12 \mathrm{c}$ & $221.43 \pm 2.23 \mathrm{~b}$ \\
$\mathrm{TFC}(\mathrm{mg} \mathrm{QUER} / \mathrm{g})$ & $4.37 \pm 0.28 \mathrm{~b}$ & $4.25 \pm 0.17 \mathrm{~b}$ & $5.01 \pm 0.13 \mathrm{a}$ & $4.79 \pm 0.24 \mathrm{ab}$ \\
\hline
\end{tabular}

1 Data represent the mean \pm standard deviation of each sample assayed in triplicate;

${ }^{2}$ Abbreviations: $\mathrm{TPC}=$ total phenolic content, $\mathrm{GAE}=$ gallic acid equivalent, $\mathrm{CT}=$ condensed tannin, $\mathrm{CAT}=$ catechin, $\mathrm{TFC}=$ total flavonoid content, $\mathrm{QUER}=$ quercetin. ${ }^{3}$ Means with different letters within a row indicate significant differences among doses by Tukey's multiple test $(p<0.05)$.

The most phenolic antioxidants present in lyophilized peanut skin extracts were condensed tannins (a total of $25.19 \%$ in peanut skins) [21], which agree with the present study. According to Tukey's multiple test $(p<0.05)$ condensed tannin content was decreased by gamma radiation (Table 1$)$. This decrease could be due to the degradation of tannins and could explain the higher total phenolic contents in the extracts [22]. Furthermore, $65.0 \mathrm{mg} / \mathrm{g}$ in catechin equivalents was reported for total flavonoid content [9]. In the present study, there was a slight increase in total flavonoids at $7.5 \mathrm{kGy}$. An increase in total flavonoid content was also reported for honeys that were gamma irradiated with $25.0 \mathrm{kGy}$ [16]. However, differently of total phenolic content, no correlation was found among gamma radiation doses and condensed tannin $(r=-0.3949)$ or gamma radiation doses and total flavonoid content $(r=0.5973)$, by Pearson's coefficient.

The DPPH assay showed increasing antioxidant activity at 5.0 and $10.0 \mathrm{kGy}$ (Figure 1), while for ABTS (Figure 2), the effect was noticeable at 5.0 and $7.5 \mathrm{kGy}$. Similarly to condensed tannin and total flavonoid content, no correlation was found between antioxidant activity (DPPH, $r=0.3011$ or ABTS, $r=0.5218$ ) and gamma radiation doses. In addition to the irradiation process, the extraction and the assay method can affect the measured total phenolic content and the antioxidant activity of the peanut skin extracts. Values of 2149 and $2789 \mu \mathrm{mol}$ TEAC/g were reported for the antioxidant activity of peanut skin extracts employing Oxygen Radical Absorbance Capacity (ORAC) using solid-liquid extraction (SLE) and microwave-assisted extraction (MAE), respectively [15]. The peanut type is another factor that influences the TEAC value. Studies with 27 peanut cultivars reported that the total antioxidant capacities from the peanut skins, measured by ABTS, ranged from 59.1 to $103.8 \mathrm{mM}$ TEAC/100 g, with a mean value of $82.3 \mathrm{mM} \mathrm{TE} / 100 \mathrm{~g}$ [23]. Different from the present study there was no significant difference in the DPPH radical scavenging capacity between irradiated (20.0 kGy) and control green tea leaves and byproducts [19]. 
Figure 1. Antioxidant activity of gamma-irradiated peanut skin extracts measured by DPPH assay. Data represent the mean \pm standard deviation of each sample assayed in triplicate. Means with different letters indicate significant differences among doses by Tukey's multiple test $(p<0.05)$.

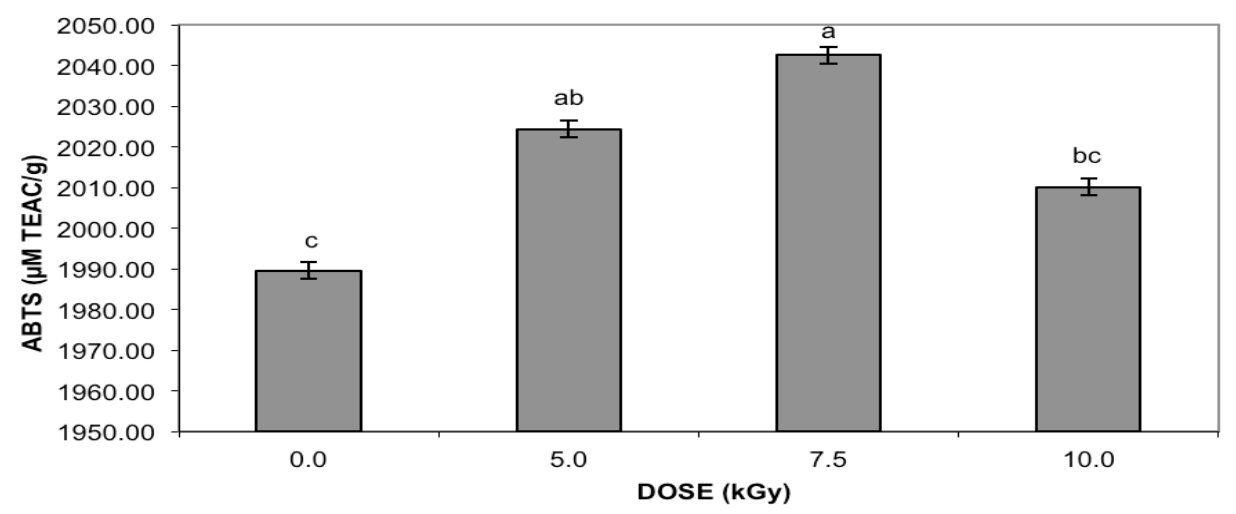

Figure 2. Antioxidant activity of gamma-irradiated peanut skin extracts measured by ABTS assay. Data represent the mean \pm standard deviation of each sample assayed in triplicate. Means with different letters indicate significant differences among doses by Tukey's multiple test $(p<0.05)$.

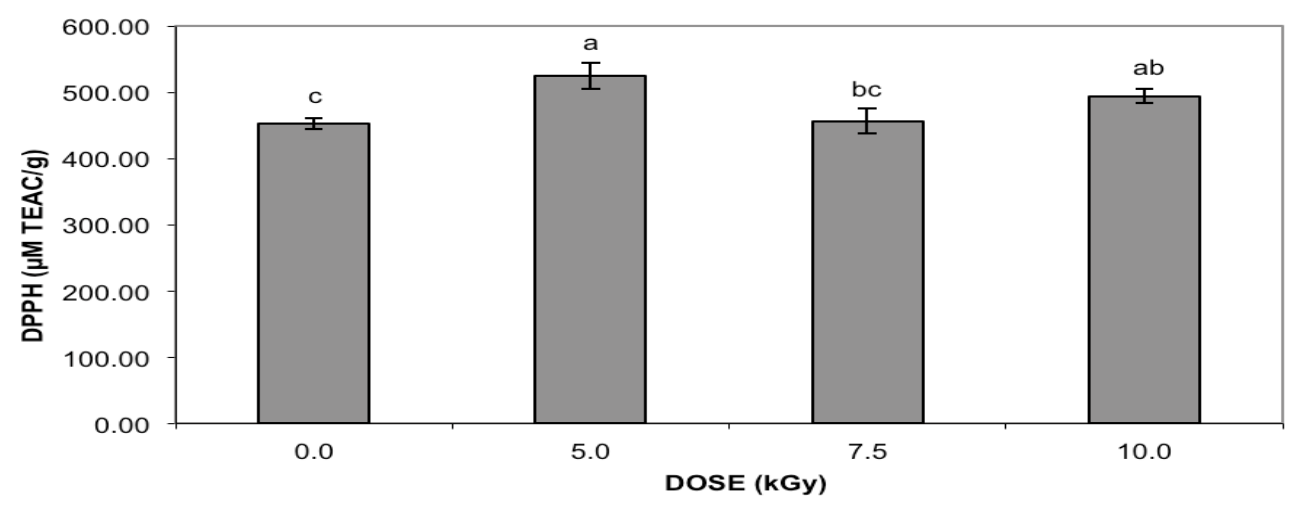

Similarly to the present study, gamma-irradiated pomegranate peel [10] presented a slight increase in antioxidant activity, measured by ABTS, at $10.0 \mathrm{kGy}$. Higher scavenging activities of non-irradiated and irradiated ethanolic extracts of peanut skins and hulls when compared to TBHQ at $50 \mu \mathrm{g} / \mathrm{mL}$ using the DPPH radical was reported [24]. At this concentration, the gamma radiation did not change the scavenging activity of the samples. The antioxidant properties of tea [18], such as free radical scavenging activity measured by the DPPH assay, were not affected by a radiation treatment with a dose of $10.0 \mathrm{kGy}$. Gamma-irradiated almond skins [11] presented the most effective antioxidant activity by reducing the absorbance of ABTS radical at 4.0 and $12.0 \mathrm{kGy}$ for samples purchased from different suppliers. Nonsignificant increases in the antioxidative capacity of cumin seeds irradiated with 1.0, 3.0, 5.0 , or $10.0 \mathrm{kGy}$ were found [25].

Dry rosemary leaf powder subjected to $30.0 \mathrm{kGy}$ of gamma radiation followed by solvent extraction with methanol, ethanol or water presented $\mathrm{EC}_{50}$ values for $\mathrm{DPPH}$ assay that decreased by $22 \%$ for ethanol and water extracts compared to the control samples. $\mathrm{EC}_{50}$ values in the reducing power test 
showed a decrease of $45 \%$ and $28 \%$ for the ethanol and water extracts, respectively. No significant difference was observed for the methanolic extracts [12].

The increase in phenolic compounds by gamma radiation could be attributed to their release from glycosidic components and the degradation of larger phenolic compounds into smaller ones by gamma irradiation [11]. The increase in isoflavones in the aglycone form and decrease in glicosidic forms were also reported as a consequence of gamma radiation [26]. In the present study, gamma radiation could have affected the extraction efficiency during the analysis and the types of compounds extracted, increasing the total phenolic content and the antioxidant activities measured by the DPPH and ABTS assays. However, to confirm this hypothesis, other parameters such as the gamma radiation induced generation of Maillard compounds [27,28], which have demonstrated antioxidant properties should be eliminated. In addition, the identification and quantification of individual phenolic compounds need to be carried out. Both of the results of the present study and results from other researchers make it possible to say that gamma radiation does not negatively affect the free radical scavenging activity.

\subsection{Analysis of the Peanut Skin Extracts Concentrations Using the Oil Stability Index Method}

The induction period from soybean oil with added peanut skin extracts is shown in Figure 3 . At $100 \mathrm{mg} / \mathrm{kg}$ peanut skin extracts presented a pro-oxidant effect. This could be due to the extraction of pro-oxidant compounds that were more active than the antioxidants extracted at this concentration. Green tea extracts also presented pro-oxidant effect in marine oil. After dechlorophyllization the extracts presented antioxidant activity [29]. These results demonstrate that there is a competition between the pro-oxidant and antioxidant compounds that can be extracted. Pro-oxidant effect was also reported for $\alpha$-tocopherol that is also known for its antioxidant properties. This behavior depends on the concentration of $\alpha$-tocopherol as well as the solvent system. In an aqueous system, the pro-oxidant effect occurs more easily [30].

Figure 3. Induction period $(\mathrm{h})$ of soybean oil with added peanut skin extracts (PSE). Data represent the mean \pm standard deviation of each sample assayed in triplicate. Means with different letters indicate significant differences among doses by Tukey's multiple test $(p<0.05)$.

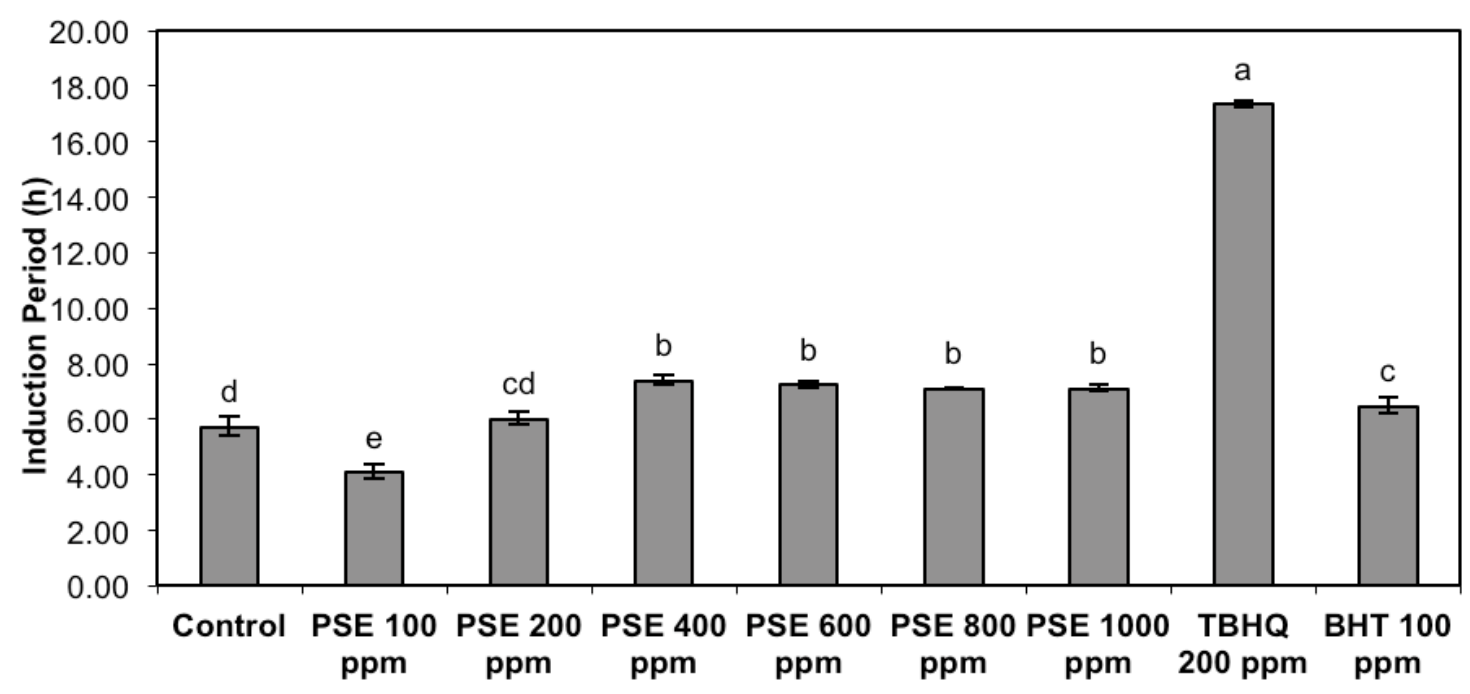


Peanut skin extracts showed the highest induction period at $400 \mathrm{mg} / \mathrm{kg}$ or more (Figure 3) once nonsignificant differences were noted from 400 to $1000 \mathrm{mg} / \mathrm{kg}$. Although the induction periods of the extracts from 400 to $1000 \mathrm{mg} / \mathrm{kg}$ demonstrated lower values than those of TBHQ, antioxidant activity exists for these concentrations when compared to the control and BHT. Canola meal extracts [31] at 100, 200, 500 and $1000 \mathrm{ppm}$ were able to reduce the peroxide value of canola oil submitted to accelerated oxidation. However, the reduction was not proportional to the concentration of the extracts, which was also noticed at the present study.

Vegetable oils used in several studies expressed TBHQ as the most effective antioxidant activity, even under high temperatures. However, the natural antioxidants from oregano extracts, rosemary, and sesame that were added to soybean oil demonstrated higher antioxidant effects than BHA or BHT [32]. Effectiveness of dechlorophyllized green tea extracts at 500 and 1000 ppm levels was superior to that of $\alpha$-tocopherol at $500 \mathrm{ppm}$ and BHA and BHT at $200 \mathrm{ppm}$, but somewhat less than that of TBHQ at 200 ppm [29], which agrees with the present study that expressed TBHQ as the most effective. Phenolic compounds extracted from peanut skins also reduced the oxidation from meat products and increased its shelf life [6].

\subsection{Antioxidant Effect of the Irradiated Peanut Skin Extracts Using the Oil Stability Index Method}

The induction periods of the soybean oil with added ethanolic extracts of gamma-irradiated peanut skins are shown in Table 2.

Table 2. Induction period (h) ${ }^{1}$ of soybean oil with added ethanolic peanut skin extracts or synthetic antioxidants.

\begin{tabular}{|c|c|c|c|c|c|c|c|}
\hline \multirow[b]{2}{*}{ Dose (kGy) } & \multirow[t]{2}{*}{ Control } & \multirow[t]{2}{*}{$\begin{array}{c}\text { TBHQ } \\
(200 \mathrm{mg} / \mathrm{kg})\end{array}$} & \multirow[t]{2}{*}{$\begin{array}{c}\text { BHT } \\
(100 \mathrm{mg} / \mathrm{kg})\end{array}$} & \multicolumn{4}{|c|}{$\begin{array}{l}\text { Ethanolic extract from peanut skins } \\
\qquad(400 \mathrm{mg} / \mathrm{kg})\end{array}$} \\
\hline & & & & 0.0 & 5.0 & 7.5 & 10.0 \\
\hline $\begin{array}{l}\text { Induction } \\
\text { period }(\mathrm{h})\end{array}$ & $5.72 \pm 0.35 \mathrm{~d}^{2}$ & $17.34 \pm 0.13 \mathrm{a}$ & $6.47 \pm 0.30 \mathrm{c}$ & $7.37 \pm 0.03 \mathrm{~b}$ & $7.22 \pm 0.07 \mathrm{~b}$ & $7.11 \pm 0.19 b$ & $7.30 \pm 0.04 \mathrm{~b}$ \\
\hline
\end{tabular}

Gamma radiation did not affect the induction period of soybean oil added to ethanolic peanut skin extracts. Although, according to Tukey's multiple test $(p<0.05)$, the antioxidant activities (DPPH and ABTS) increased with irradiation, the results were not observed during the Oil Stability Index assay. In fact, according to Pearson's coefficient, no correlation was found between gamma radiation and antioxidant activity (DPPH or ABTS). It is possible to conclude that gamma radiation does not affect the antioxidant property of the peanut skin extracts and, in turn, the oxidative protection of soybean oil. Gamma-irradiated peanut skins showed longer induction periods than BHT and the control samples. However, they presented lower induction periods than TBHQ. These results agree with the findings of studies [11] that reported that the antioxidant properties of almond skin extracts added in soybean oil submitted to oxidation initiated with ferric chloride were not affected by gamma radiation at 2.8, 4.8, $8.8,12.7$, or $16.3 \mathrm{kGy}$ when analyzed by peroxide value. 
The lipid peroxidation of fish oil emulsion, measured by the presence of thiobarbituric acid reactive substances (TBARS), was inhibited by approximately 76\%, while the superoxide radicals were scavenged by approximately $72 \%$ to $75 \%$ in the presence of tea leaves infusion in vitro. Gamma radiation doses of 1.0, 2.0, 5.0, or $10.0 \mathrm{kGy}$ did not affect the antioxidant properties of the extracts prepared from the tea leaves [18].

Green tea leaf extract [33] decreased the oxidation in raw and cooked pork patties stored for 15 days under $4{ }^{\circ} \mathrm{C}$. The TBARS value of the raw pork patties increased during the 15 days of storage in all treatments. However, the TBARS values of the patties with added freeze-dried green tea leaf extract powder $(0.1 \%)$ were significantly lower than those of the control. There was no significant difference between irradiation with $20.0 \mathrm{kGy}$ and non-irradiated extracts.

\section{Experimental Section}

\subsection{Material}

The peanut skin samples from cultivar IAC Runner 886 (crop year 2009/2010) were obtained from CAP-Agroindustrial, Dumont, São Paulo State, Brazil. The samples were separated in polyethylene plastic bags and irradiated with 5.0, 7.5, or $10.0 \mathrm{kGy}$ at a dose rate of $7.5 \mathrm{kGy} / \mathrm{h}$. One package was not irradiated for use as a control. Irradiation process was carried out in the city of São Paulo, São Paulo State, Brazil, using a multipurpose Cobalt-60 $\gamma$-irradiation facility from Nuclear Energy Research Institute (IPEN). IPEN is an autarchy, associated to the University of São Paulo-supported and operated technically and administratively by the National Nuclear Energy Commission (CNEN).

\subsection{Methods}

\subsubsection{Total Phenolics}

Total phenolic content was analyzed in methanolic extracts with a concentration of $0.40 \mathrm{mg} / \mathrm{mL}$, according to the Folin-Ciocalteu method [34]. First, $0.02 \mathrm{~g}$ of peanut skins in $50.00 \mathrm{~mL}$ of methanol was shaken for $20 \mathrm{~min}$ at room temperature. Second, the extract was centrifuged at $700 \mathrm{rpm}$ for $15 \mathrm{~min}$, and the supernatant was collected and transferred to a volumetric flask. Third, the volume was made up to $50.00 \mathrm{~mL}$, and it was used as the final extract. Fourth, the extract $(0.50 \mathrm{~mL})$, deionized water $(4.0 \mathrm{~mL})$, and Folin-Ciocalteu reagent $(0.50 \mathrm{~mL})$ were added into flasks and mixed thoroughly. After $3 \mathrm{~min}, 1.00 \mathrm{~mL}$ of a $\mathrm{Na}_{2} \mathrm{CO}_{3}$ saturated solution $(20.00 \mathrm{~g}$ in $70.00 \mathrm{~mL}$ of water) was added, and the mixture was shaken in a water bath at $37{ }^{\circ} \mathrm{C}$ for $30 \mathrm{~min}$. Finally, the absorbance was determined at $760 \mathrm{~nm}$ using a Shimadzu UV-1800 spectrophotometer (Shimadzu Corporation; Japan). The results were expressed as milligram gallic acid equivalents.

\subsubsection{Condensed Tannins}

Condensed tannins were evaluated in methanolic extracts with a concentration of $2.00 \mathrm{mg} / \mathrm{mL}$, according to the method [35]. This extract was obtained by shaking $0.02 \mathrm{~g}$ of skins in $10 \mathrm{~mL}$ of methanol for $20 \mathrm{~min}$ and then centrifuging for $20 \mathrm{~min}$ at $4000 \mathrm{rpm}$. The supernatant was added $(0.1 \mathrm{~mL})$ into tubes that received $5.00 \mathrm{~mL}$ of a $1: 1$ solution prepared with vanillin $1 \%(\mathrm{w} / \mathrm{v})$ in 
methanol and $\mathrm{HCl} 8 \%(\mathrm{v} / \mathrm{v})$ in methanol. The tubes were then shaken in a water bath at $30{ }^{\circ} \mathrm{C}$, and the absorbance was determined at $500 \mathrm{~nm}$ using a Shimadzu UV-1800 spectrophotometer (Shimadzu Corporation; Japan). The results were expressed as milligram catechin equivalents.

\subsubsection{Total Flavonoids}

Total flavonoids were determined according to the method [36]. Peanut skin extracts were obtained with $70 \%$ ethanol at $20.00 \mathrm{mg} / \mathrm{mL}$ concentration. To obtain this extract, $1.00 \mathrm{~g}$ of peanut skins was immersed in $50 \mathrm{~mL}$ of $70 \%$ ethanol for $24 \mathrm{~h}$ at room temperature in the dark. The extract was then filtered and centrifuged at $700 \mathrm{rpm}$ for $15 \mathrm{~min}$. The supernatant was transferred to a volumetric flask, and the volume was made up to $50 \mathrm{~mL}$; this was considered to be the final extract. Two tube series were prepared, and $0.5 \mathrm{~mL}$ of the extract was added to all of the tubes. In the first series, $4.3 \mathrm{~mL}$ of $80 \%$ ethanol was added to tubes that would receive an $\mathrm{Al}\left(\mathrm{NO}_{3}\right)_{3}$ solution. In the second series, $4.4 \mathrm{~mL}$ of $80 \%$ ethanol was added to the tubes that would not receive any $\mathrm{Al}\left(\mathrm{NO}_{3}\right)_{3}$. All the tubes then received $0.1 \mathrm{~mL}$ of a $1.00 \mathrm{M}$ solution of $\mathrm{CH}_{3} \mathrm{COOK}$. At this point, the first series of tubes received $0.1 \mathrm{~mL}$ of a $10 \% \mathrm{Al}\left(\mathrm{NO}_{3}\right)_{3}$ solution. All the tubes were shaken for $40 \mathrm{~min}$, and then absorbance was determined at $415 \mathrm{~nm}$ using a Shimadzu UV-1800 spectrophotometer (Shimadzu Corporation; Japan). The calculations took into account the differences in the readings between the treatments. The final results were expressed as milligram quercetin equivalents.

\subsubsection{DPPH Free Radical Scavenging Activity}

Antioxidant activity was measured using the DPPH (2,2-diphenyl-1-picrylhydrazyl) radical assay [37] of ethanolic extracts with a $0.20 \mathrm{mg} / \mathrm{mL}$ concentration. The extracts were obtained from $0.01 \mathrm{~g}$ peanut skins and $50.00 \mathrm{~mL}$ of ethanol that were shaken for $15 \mathrm{~min}$ and centrifuged for $10 \mathrm{~min}$ at $2000 \mathrm{rpm}$. The supernatant $(0.50 \mathrm{~mL})$ was added to ethanol $(3.0 \mathrm{~mL})$ and a $60.00 \mu \mathrm{M} \mathrm{DPPH}$ solution. The absorbance was determined at $517 \mathrm{~nm}$ using a Shimadzu UV-1800 spectrophotometer (Shimadzu Corporation; Japan), after $45 \mathrm{~min}$ in the dark. DPPH free radical scavenging activity was calculated using the equation below:

DPPH free radical scavenging activity $(\%)=\left[\left(\mathrm{Abs}_{\text {control }}-\mathrm{Abs}_{\text {sample }}\right) /\left(\mathrm{Abs}_{\text {control }}\right)\right] \times 100$

where $\mathrm{Abs}_{\text {control }}$ was the absorbance of DPPH radical + ethanol; $\mathrm{Abs}_{\text {sample }}$ is the absorbance of DPPH radical + peanut skin extract or trolox. The results were expressed as Trolox equivalent antioxidant capacity (TEAC).

\subsubsection{ABTS Free Radical Scavenging Activity}

In this assay [38] the ABTS radical (2,2'-azino-bis(3-ethylbenzothiazoline-6-sulphonic acid)), which is generated by oxidation with potassium persulfate, was utilized in ethanolic extracts with a $0.40 \mathrm{mg} / \mathrm{mL}$ concentration. A stock solution of ABTS was prepared at $7.00 \mathrm{mM}$ one day before the analysis, and the work solution was prepared by diluting the stock solution to $0.70 \mathrm{~nm} \pm 0.02 \mathrm{~nm}$ at $734 \mathrm{~nm}$ absorbance. The extracts were obtained using the same method described for the DPPH assay with $0.02 \mathrm{~g}$ of peanut skins added into $50.00 \mathrm{~mL}$ of ethanol. The supernatant $(20.00 \mu \mathrm{L})$ was added into a quartz cuvette along with the ABTS radical solution $(2.00 \mathrm{~mL})$, and the absorbance was 
determined at $734 \mathrm{~nm}$ for 6 min using a Shimadzu UV-1800 spectrophotometer (Shimadzu Corporation; Japan). ABTS free radical scavenging activity was calculated using the equation below:

ABTS free radical scavenging activity $(\%)=\left[\left(\mathrm{Abs}_{\text {control }}-\mathrm{Abs}_{\text {sample }}\right) /\left(\mathrm{Abs}_{\mathrm{control}}\right)\right] \times 100$

where $\mathrm{Abs}_{\text {control }}$ was the absorbance of ABTS radical + ethanol; $\mathrm{Abs}_{\text {sample }}$ is the absorbance of ABTS radical + peanut skin extract or trolox. The results were expressed as TEAC.

\subsubsection{Rancimat Oxidative Stability}

The Oil Stability Index was evaluated according to Cd 12b-92 method [39] in Metrohm's 743 Rancimat equipment (Metrohm Ltd, CH-9101 Herisau, Switzerland). Five grams of refined-bleached-deodorized (RBD) soybean oil free from synthetic antioxidants were added to $1 \mathrm{~mL}$ ethanolic peanut skins extracts and heated at $110{ }^{\circ} \mathrm{C}$ with an airflow of $9 \mathrm{~L} / \mathrm{h}$ in the sample reaction tubes. To obtain the extracts used in this test, the yield of total phenolic content, as found in Section 2.2.1, was considered. To prepare each $100 \mathrm{mg} / \mathrm{kg}$ extract, $62.25 \mathrm{mg}$ of peanut skins were immersed in $10.0 \mathrm{~mL}$ of ethanol or hexane for $24 \mathrm{~h}$ at room temperature in the dark. The extract was then filtered and centrifuged at $700 \mathrm{rpm}$ for $15 \mathrm{~min}$. The supernatant was transferred to a volumetric flask, and the volume was made up to $10.0 \mathrm{~mL}$. The induction period was expressed in hours.

\subsubsection{Statistical Analysis}

The experimental design was randomized with three replications. The results were analyzed (ANOVA) using the F-test. Mean comparisons were tested based on Tukey $(p<0.05)$ by SAS software. Correlation analyses were carried out with ASSISTAT 7.6 program.

\section{Conclusions}

Peanut skin samples contain bioactive compounds such as polyphenols, condensed tannins, and flavonoids. The antioxidant activity of peanut skins was confirmed using the DPPH and ABTS in vitro methods. The Oil Stability Index method confirmed that the ethanolic extracts retarded the oxidation process of soybean oil; besides DPPH and ABTS have shown increasing antioxidant activity by gamma radiation the Oil Stability Index method demonstrated that gamma radiation does not affect the antioxidant properties of the peanut skin ethanolic extracts when added in soybean oil. Total phenolic content, and antioxidant activity in vitro, are good indicators for measuring the antioxidant properties from plant extracts. However, tests in model system are indispensable in the assessment of the results of treatments such as gamma radiation.

\section{Acknowledgments}

CNEN—National Nuclear Energy Commission (M.Sc. scholarship); FAPESP—São Paulo Research Foundation (Financial Support 2009/18215-8); CAP_Agroindustrial (Peanut skin samples). 


\section{References}

1. Lou, H.; Yamazaki, Y.; Sasaki, T.; Uchida, M.; Tanaka, H.; Oka, S. A-type proanthocyanidins from peanut skins. Phytochemistry 1999, 51, 297-308.

2. Lou, H.; Yuan, H.; Yamazaki, Y.; Sasaki, T.; Oka, S. Alkaloids and flavonoids from peanut skins. Planta Med. 2001, 67, 345-349.

3. Nepote, V.; Grosso, N.R.; Gusmán, C.A. Radical scavenging activity of extracts of Argentine peanut skins (Arachis hypogaea) in relation to its Trans-Resveratrol content. J. Argent. Chem. Soc. 2004, 92, 41-49.

4. Lou, H.; Yuan, H.; Ma, B.; Ren, D.; Ji, M.; Oka, S. Polyphenols from peanut skins and their free radical-scavenging effects. Phytochemistry 2004, 65, 2391-2399.

5. Nepote, V.; Grosso, N.R.; Gusmán, C.A. Optimization of extraction of phenolic antioxidants from peanut skins. J. Sci. Food Agric. 2005, 85, 33-38.

6. O'Keefe, S.F.; Wang, H. Effects of peanut skin extract on quality and storage stability of beef products. Meat Sci. 2006, 73, 278-286.

7. Yu, J.; Ahmedna, M.; Goktepe, I.; Dai, J. Peanut skin procyanidins: Composition and antioxidant activities as affected by processing. J. Food Compos. Anal. 2006, 19, 364-371.

8. Verstraeten, S.V.; Hammerstone, J.F.; Keen C.L.; Fraga, C.G.; Oteiza, P.I. Antioxidant and membrane effects of procyanidin dimers and trimers isolated from peanut and cocoa. J. Agric. Food Chem. 2005, 53, 5041-5048.

9. Wang, J.; Yuan, X.; Jin, Z.; Tian, Y.; Song, H. Free radical and reactive oxygen species scavenging activities of peanut skins extract. Food Chem. 2007, 104, 242-250.

10. Mali, A.B.; Khedkar, K.; Lele, S.S. Effect of gamma irradiation on total phenolic content and in vitro antioxidant activity of pomegranate (Punica granatum L.) peels. Food Nutr. Sci. 2011, 2, 428-433.

11. Harrison, K.; Were, L.M. Effect of gamma irradiation on total phenolic content yield and antioxidant capacity of Almond skin extracts. Food Chem. 2007, 102, 932-937.

12. Pérez, M.B.; Calderón, N.L.; Croci, C.A. Radiation-induced enhancement of antioxidant activity in extracts of rosemary (Rosmarinus officinalis L.). Food Chem. 2007, 104, 585-592.

13. Variyar, P.S.; Limaye, A.; Sharma, A. Radiation-induced enhancement of antioxidant contents of soybean (Glycine max Merrill). J. Agric. Food Chem. 2004, 52, 3385-3388.

14. Štajner, D.; Milošević, M.; Popović, B.M. Irradiation effects on phenolic content, lipid and protein oxidation and scavenger ability of soybean seeds. Int. J. Mol. Sci. 2007, 8, 618-627.

15. Ballard, T.S.; Mallikarjunan, P.; Zhou, K.; O’Keefe, S. Microwave-assisted extraction of phenolic antioxidant compounds from peanut skins. Food Chem. 2010, 120, 1185-1192.

16. Hussein, S.Z.; Yusoff, K.M.; Makpol, S.; Yusof, I.A.M. Antioxidant capacities and total phenolic contents increase with gamma irradiation in two types of Malaysian honey. Molecules 2011, 16, 6378-6395.

17. Hussain, P.R.; Wani, A.M.; Meena, R.S.; Dar, M.A. Gamma irradiation induced enhancement of phenylalanine ammonia-lyase (PAL) andantioxidant activity in peach (Prunus persica Bausch, $\mathrm{Cv}$. Elberta). Radiat. Phys. Chem. 2010, 79, 982-989. 
18. Mishra, B.B.; Gautam, S.; Sharma, A. Microbial decontamination of tea (Camellia sinensis) by gamma radiation. J. Food Sci. 2006, 71, 151-156.

19. Lee, N.A.; Jo, C.; Sohn, S.H.; Kim, J.K.; Byun, M.W. Effects of gamma irradiation on the biological activity of green tea byproduct extracts and a comparison with green tea leaf extracts. J. Food Sci. 2006, 71, 269-274.

20. Chiang, Y.C.; Huang, G.J.; Ho, Y.L.; Hsieh, P.C.; Chung, H.P.; Chou, F.I.; Chang, Y.S. Influence of gamma irradiation on microbial load and antioxidative characteristics of Polygoni multiflori Radix. Proc. Biochem. 2011, 46, 777-782.

21. Ha, H.V.; Pokorný, J.; Sakurai, H. Peanut skins antioxidants. J. Food Lipids 2007, 14, 298-314.

22. Variyar, P.S.; Bandyopadhyay, C.; Thomas, P. Effect of gamma-irradiation on the phenolic acids of some Indian spices. Int. J. Food Sci. Technol. 1998, 33, 533-537.

23. Chukwumah, Y.; Walker, L.T.; Verghese, M. Peanut skin color: A biomarker for total polyphenolic content and antioxidative capacities of peanut cultivars. Int. J. Mol. Sci. 2009, 10, 4941-4952.

24. Ali, H.G.M.; Abdeldaiem, M.H. Effect of gamma irradiation on the antioxidant activity of ethanolic extracts from peanut hulls. Isot. Rad. Res. 2010, 42, 125-138.

25. Kim, J.H.; Shin, M.H.; Hwang, Y.J.; Srinivasan, P.; Kim, J.K.; Park, H.J.; Byun, M.W.; Lee, J.W. Role of gamma irradiation on the natural antioxidants in cumin seeds. Radiat. Phys. Chem. 2009, 78, 153-157.

26. Variyar, P.S.; Limaye, A.; Sharma, A. Radiation-induced enhancement of antioxidant contents of soybean (Glycine max Merrill). J. Agric. Food Chem. 2004, 52, 3385-3388.

27. Chawla, S.P.; Chander, R.; Sharma, A. Antioxidant properties of Maillard reaction products obtained by gamma-irradiation of whey proteins. Food Chem. 2009, 116, 122-128.

28. Rao, M.S.; Chawla, S.P.; Chander, R.; Sharma, A. Antioxidant potential of Maillard reaction products formed by irradiation of chitosan-glucose solution. Carbohydr. Polym. 2011, 83, 714-719.

29. Wanasundara, U.N.; Shahidi, F. Antioxidant and pro-oxidant activity of green tea extracts in marine oils. Food Chem. 1998, 63, 335-342.

30. Cillard, J., Cillard, P.; Cormier, M.; Girre, L. $\alpha$-Tocopherol prooxidant effect in aqueous media: Increased autoxidation rate of linoleic acid. J. Am. Oil Chem. Soc. 1980, 57, 252-255.

31. Shahidi, F.; Wanasundara, U. Effect of natural antioxidants on the stability of canola oil. Dev. Food Sci. 1995, 37A, 469-479.

32. Ramalho, V.C.; Jorge, N. Antioxidantes utilizados em óleos, gorduras e alimentos gordurosos. Quim. Nova. 2006, 29, 755-760.

33. Jo, C.; Son, J.H.; Son, C.B.; Byun, M.W. Functional properties of raw and cooked pork patties with added irradiated, freeze-dried green tea leaf extract powder during storage at $4{ }^{\circ} \mathrm{C}$. Meat Sci. 2003, 64, 13-17.

34. Swain, T., Hillis, W.E. The phenolic constituents of Prunus domestica. 1. The quantitative analises of phenolic constituents. J. Sci. Food Agric. 1959, 10, 63-68.

35. Price, M.L.; Hagerman, A.E.; Butler, L.G. Tannin content of cowpeas, chickpeas, pigeon peas and mung beans. J. Agric. Food Chem. 1980, 28, 459-461.

36. Jurd, L. Aluminum complexes of phenolic flavones. Spectral and structural correlations. Phytochemistry 1969, 8, 445-462. 
37. Brand-Williams, W.; Cuvier, M.E.; Berset, C. Use of a free radical method to evaluate antioxidant activity. Lebensm. Wiss. Technol. 1995, 28, 25-30.

38. Re, R.; Pellegrini, N.; Proteggente, A.; Pannala, A.; Yang, M.; Rice-Evans, C. Antioxidant activity applying an improved ABTS radical cation decolorization assay. Free Radic. Biol. Med. 1999, 26, 1231-1237.

39. American Oil Chemists' Society (AOCS). Method Cd12b-92. In Official Methods and Recommended Practices of the American Oil Chemists' Society, 5th ed.; AOCS: Champaign, IL, USA, 2003.

(C) 2012 by the authors; licensee MDPI, Basel, Switzerland. This article is an open access article distributed under the terms and conditions of the Creative Commons Attribution license (http://creativecommons.org/licenses/by/3.0/). 